\title{
Could we find any signal of the stratosphere-ionosphere coupling in Antarctica?
}

\author{
Marco Pietrella $\left({ }^{1}\right)$, Edward S. Kazimirovsky $\left({ }^{2}\right)$, Giorgiana De Franceschi $\left({ }^{1}\right)$, Paolo Grigioni $\left(^{3}\right)$ \\ and Carlo Scotto $\left({ }^{1}\right)$ \\ (1) Istituto Nazionale di Geofisica e Vulcanologia, Dept. RM2-UF/FAA, Roma, Italy \\ ${ }^{2}{ }^{2}$ Institute of Solar-Terrestrial Physics, Russian Academy of Sciences, Irkutsk, Russia
}

$\left(^{3}\right)$ ENEA Casaccia, S. Maria di Galeria (RM), Italy

\begin{abstract}
An investigation searching for a possible coupling between the lower ionosphere and the middle atmosphere in Antarctica is here performed on the basis of stratospheric vertical temperature profiles and ionospheric absorption data observed at the Antarctic Italian Base of Terra Nova Bay $\left(74.69^{\circ} \mathrm{S}, 164.12^{\circ} \mathrm{E}\right)$ during local summer time. The result obtained by applying a multi-regression analysis and a Superimposed Epoch Analysis (SEA) shows a statistically significant ionosphere-stratosphere interaction. In particular, by selecting stratospheric temperature maxima occurring at different heights as the referring epoch («zero day») for the SEA approach, the ionospheric absorption is found to show a positive and/or negative trend (several days) around it. The tendency for an increasing/decreasing absorption is obtained for temperature maxima occurring below/above the stratospheric level of about $17-19 \mathrm{~km}$, respectively.
\end{abstract}

Key words polar ionosphere - middle-upper atmosphere interaction

\section{Introduction}

Geophysicists have extensively discussed the problem of a stratosphere-ionosphere interaction during the last decades. It has become apparent that the ionosphere cannot be studied properly as merely magneto-active plasma without considering the general properties of the atmosphere. The lower ionosphere is the region where the solar activity

Mailing address: Dr. Marco Pietrella, Istituto Nazionale di Geofisica e Vulcanologia, Dept. RM2-UF/FAA, Via di Vigna Murata 605, 00143 Roma, Italy; e-mail: pietrella@ingv.it (controlling the higher ionospheric regions) and the meteorological influences (controlling the lower atmospheric regions) become comparable. Under some circumstances, the meteorological parameters control the variability in the lower ionosphere.

It is now accepted that some reasons for ionospheric variability could be sought in the dynamic interaction between lower and upper atmosphere. Many discoveries and experimental results have confirmed the existence of detailed correlations between the parameters of the lower atmosphere and the ionosphere (see, e.g., Kazimirovsky and Kokourov, 1991 and references therein). As part of the physical mechanism for the «coupling from below» the influence of upward propagating internal atmospheric waves may be considered. Planetary waves, tides and acoustic-gravity waves are essential sources of 
energy and momentum for the thermosphere and ionosphere (Wickwar and Carlsson, 1999). It seems likely that there could be some events in the mid-latitude ionosphere due to the effect of atmospheric oscillations such as: winter anomaly of the ionospheric absorption of radio waves, sporadic- $E$ layer $\left(E_{s}\right)$ occurrence and structure, thermospheric wind regime, Travelling Ionospheric Disturbances (TID), day-to-day ionospheric variability, spread- $F$ events, etc. In particular, the winter anomaly is under «meteorological control» (Taubenheim, 1983) and the major mechanisms are the increased ion production rate due to an increase in NO concentration, and the decreased loss rate due to removal of water-cluster ions. Both may be regarded as the effects of a large-scale transport of species from the auroral zone due to changes in the circumpolar wind pattern reaching from the stratosphere up to the ionospheric $D$-region.

Ionospheric absorption is the most suitable parameter to «feel» the meteorological influences on the lower ionosphere because it depends on the relative changes in the electron density and the collision frequency between electrons and neutral air particles. These changes could be subjected to variations in the lower thermospheric composition, which can originate from dynamical processes. These processes, in turn, appear to be (at least partly) related to stratospheric changes.

The first attempts to find the signal of the stratosphere-ionosphere interaction were carried out on the basis of ionospheric absorption and stratospheric temperature data: the discovery of a relation between increases in temperature at the $10 \mathrm{mb}$ level and the absorption of radiowaves in the ionospheric $D$-region, established for the first time the existence of a link between the stratosphere and the lower ionosphere (Bossolasco and Elena, 1963).

The discovery of a correlation between the winter anomaly observed at middle latitudes and the sudden stratospheric warming which, as known at present, are connected with planetary wave activity (Shapley and Beynon, 1965; Bossolasco and Elena, 1967), became a significant new part of the upper atmosphere physics concerning the stratosphere-ionosphere coupling which may be generally defined as any association between the variability of a parameter in the stratosphere with one in the ionosphere. The majority of the results concern the Northern Hemisphere at middle latitudes: by using the Superimposed Epochs Analysis (SEA) a very clearly positive association between the winter anomaly and the stratospheric warming was established, and a tendency for subsidiary absorption maxima to recur at an interval of about 5-8 days before and after a stratospheric warming was found (Shapley and Beynon, 1965).

Some experimental investigations have been carried out on the stratosphere-ionosphere coupling in the Southern middle latitudes Hemisphere (40-50 S): the SEA performed to investigate the effect of stratospheric warming on the ionospheric absorption as measured by $f_{\min }$ (the lowest frequency of reflection wave recorded in the ionogram), still established a positive correlation between temperature and ionospheric absorption, but, unlike the Northern Hemisphere, a day-to day variation in $f_{\min }$ maxima is of about 2-4 days. Moreover, the $f_{\min }$ values several days before the temperature maximum are greater than those observed several days afterwards. So particle precipitation should have a marked effect on the stratosphere as well as on the ionosphere, but ionospheric absorption is still a useful measure for investigating the effects due to meteorological disturbances (Essex and Morton, 1974; Fraser and Thorpe, 1976).

Very few observational studies for stratosphere-ionosphere coupling have been made at high latitudes. There were some results for North-East Siberia, i.e. at northern subauroral latitudes (Kershengolts, 1986), where some correlations between stratospheric temperatures and $F_{2}$-region parameters have been found by concluding that the sign of correlation depends on the epoch of solar activity.

To extend our knowledge on the middleupper atmosphere interaction, here the preliminary results are reported concerning multi-regression and Superimposed Epoch analyses applied to ionospheric absorption and stratospheric temperature data observed in Antarctica during austral summer time. The data 
Analysis is described in Section 2 and the results are shown in Section 3. Concluding remarks are finally given in Section 4.

\section{Data used and method of analysis}

Since 1993, in the frame of PNRA (Italian Program for Antarctic Researches), the INGV (Istituto Nazionale di Geofisica e Vulcanologia Rome, Italy) maintains an Ionospheric Observatory and two Riometer stations at the Italian Antarctic Base of Terra Nova Bay (geographic coordinates: 74.69 S, $164.12 \mathrm{E}$; geomagnetic coordinates: $77.34 \mathrm{~S}, 279.41 \mathrm{E}$ ) for the vertical ionospheric sounding and for the cosmic noise measurements at the frequencies of $30 \mathrm{MHz}$ and $38.2 \mathrm{MHz}$. At the same location, during austral summer time, measurements of tropospheric and stratospheric parameters, acquired by balloons launched each day around 12.00 UT and 00.00 UT (Bacci and Pellegrini, 1996; Grigioni, 1996), are regularly provided by the ENEA (Ente per le Nuove Tecnologie L'Energia e L'Ambiente, Rome, Italy).

Ionospheric absorption data, derived from the cosmic noise measurements at $30 \mathrm{MHz}$ (A2 method, De Franceschi et al., 1997), stratospheric temperature data, derived from the vertical temperature profiles obtained by balloons in the range of geopotential altitudes $13-26 \mathrm{~km}$, the solar flux $F_{10.7}$, and the time weighted magnetic index ap $(\tau=0.8)$ (see, e.g., Perrone and De Franceschi,1999 and reference therein) are considered as the data base during the period 1 December 1994 - 15 February 1995. As the stratospheric temperature values are available at $00.00 \mathrm{UT}$ and $12.00 \mathrm{UT}$, the ionospheric absorption and the magnetic index used in the analyses are related to the same time of the day, while for the solar index the daily value is processed. The choice of $a p(\tau=0.8)$ to represent the magnetic activity influence on the ionosphere (at least in the $F$ region) is due to the fact that several recent investigations pointed out a better correlation between the magnetic perturbation and the ionospheric variability if a time weighted magnetic index, such as ap $(\tau=0.8)$, is used instead of the well-known planetary ap.
The multi-regression and Superimposed Epoch analyses, applied separately to the case of $h=00.00 \mathrm{UT}$ and 12.00 UT and for each geopotential height $l=13,14 \ldots .26 \mathrm{~km}$, are briefly summarised as follows.

\subsection{Multiregression analysis}

The stratospheric temperature and the ionospheric absorption data series $(T(h, l)$ and $A(h))$ are considered with the daily solar flux $F_{10.7}$ and the index ap $(\tau=0.8, h)$ in the following multi-regression formula:

$$
\begin{gathered}
A(h)=a(h, l)+b(h, l) T(h, l)+c(h, l) F_{10.7}+ \\
+d(h, l) \operatorname{ap}(\tau=0.8, h) .
\end{gathered}
$$

The numerical coefficients $a(h, l), b(h, l), c(h, l)$, and $d(h, l)$, have been calculated by means of the least squares method to evaluate the meteorological, solar and magnetic influence on the ionospheric absorption. Fisher's test (confidence level $=95 \%$ ) has been performed to check the statistical significance of the model.

\subsection{Superimposed Epochs Analysis (SEA)}

The SEA has been applied to search for a possible influence of the stratospheric temperature on the ionospheric absorption. The temperature data series, $T(h, l)$ (whose values ranged between about $-32{ }^{\circ} \mathrm{C}$ and $-42{ }^{\circ} \mathrm{C}$ ), and absorption data series, $A(h)$ (whose values ranged between about 0.014 and $0.11 \mathrm{~dB}$ ) from 1 December 1994 to 15 February 1995 have been considered.

Firstly the temperature maxima $T_{\max }(h, l)$ were selected as the «zero day» epochs and 6 days before and after each «zero day» were taken into account:

- For each $T_{\max }(h, l)$, the corresponding values of the ionospheric absorption were considered to calculate the average value of the absorption corresponding to the «zero day».

- Then, the daily average absorption values were calculated at 1,2...6 days before and after 
the «zero day». In this way the average behaviour of the ionospheric absorption 6 days before and 6 days after $T_{\max }(h, l)$ was evaluated for each $h$ and $l$.
- The average levels of ionospheric absorption and the standard deviations before and after the «zero day» were also calculated to define the statistically significant results.

Table I. Results of multi-regression analysis in the range $13-26 \mathrm{~km}$ for data set at $12.00 \mathrm{UT}$ : statistically significant results are in bold.

\begin{tabular}{ccccccc}
\hline \hline$l$ & $a(h, l)$ & $b(h, l)$ & $c(h, l)$ & $d(h, l)$ & $F$ & $F_{\alpha}$ \\
\hline $13 \mathrm{~km}$ & -.01 & -.0002 & .0007 & .0003 & 0.41 & $\cong 2.76$ \\
$14 \mathrm{~km}$ & .08 & .0034 & .0014 & .0003 & 1.40 & $\cong 2.76$ \\
$\mathbf{1 5} \mathbf{~ k m}$ & $\mathbf{. 2}$ & $\mathbf{. 0 0 7 9}$ & $\mathbf{. 0 0 1 7}$ & $\mathbf{. 0 0 0 3}$ & $\mathbf{6 . 7 6}$ & $\cong \mathbf{2 . 7 6}$ \\
$\mathbf{1 6} \mathbf{~ k m}$ & $\mathbf{. 3 2}$ & $\mathbf{. 0 0 9 1}$ & $\mathbf{. 0 0 1 1}$ & $\mathbf{. 0 0 0 4}$ & $\mathbf{7 . 8 8}$ & $\cong \mathbf{2 . 7 6}$ \\
$\mathbf{1 7} \mathbf{~ k m}$ & $\mathbf{. 2 5}$ & $\mathbf{. 0 0 6 3}$ & $\mathbf{. 0 0 0 6}$ & $\mathbf{. 0 0 0 6}$ & $\mathbf{4 . 3 1}$ & $\cong \mathbf{2 . 7 6}$ \\
$\mathbf{1 8} \mathbf{~ k m}$ & $\mathbf{. 2 1}$ & $\mathbf{. 0 0 5 3}$ & $\mathbf{. 0 0 0 5}$ & $\mathbf{. 0 0 0 6}$ & $\mathbf{2 . 8 3}$ & $\cong \mathbf{2 . 7 6}$ \\
$19 \mathrm{~km}$ & .20 & .0047 & .0003 & .0006 & 2.58 & $\cong 2.76$ \\
$20 \mathrm{~km}$ & .11 & .0024 & .0004 & .0006 & .089 & $\cong 2.76$ \\
$21 \mathrm{~km}$ & .07 & .0015 & .0005 & .0006 & 0.55 & $\cong 2.76$ \\
$22 \mathrm{~km}$ & .05 & .0008 & .0004 & .0004 & 0.27 & $\cong 2.76$ \\
$23 \mathrm{~km}$ & .02 & .0008 & .0007 & .0005 & 0.39 & $\cong 2.76$ \\
$24 \mathrm{~km}$ & -.07 & -.0005 & .0013 & .0002 & 0.90 & $\cong 2.76$ \\
$25 \mathrm{~km}$ & -.09 & -.0011 & .0013 & .0001 & 0.89 & $\cong 2.76$ \\
$26 \mathrm{~km}$ & -.09 & -.0012 & .0013 & .0001 & 0.81 & $\cong 2.76$ \\
\hline
\end{tabular}

Table II. Results of multi-regression analysis in the range 13-26 km for data set at 00.00 UT: statistically significant results are in bold.

\begin{tabular}{ccccccc}
\hline \hline$l$ & $a(h, l)$ & $b(h, l)$ & $c(h, l)$ & $d(h, l)$ & $F$ & $F_{\alpha}$ \\
\hline $13 \mathrm{~km}$ & -.09 & -.0013 & .0010 & .0014 & 1.61 & $\cong 2.76$ \\
$14 \mathrm{~km}$ & .06 & .0039 & .0018 & .0014 & 2.46 & $\cong 2.76$ \\
$\mathbf{1 5} \mathbf{~ k m}$ & .29 & $\mathbf{. 0 1 0 5}$ & $\mathbf{. 0 0 2 3}$ & $\mathbf{. 0 0 1 3}$ & $\mathbf{8 . 8 0}$ & $\cong \mathbf{2 . 7 6}$ \\
$\mathbf{1 6} \mathbf{~ k m}$ & $\mathbf{2 6}$ & $\mathbf{. 0 0 8 6}$ & $\mathbf{. 0 0 1 6}$ & $\mathbf{. 0 0 1 2}$ & $\mathbf{8 . 8 0}$ & $\cong \mathbf{2 . 7 6}$ \\
$\mathbf{1 7} \mathbf{~ k m}$ & $\mathbf{2 5}$ & $\mathbf{. 0 0 7 9}$ & $\mathbf{. 0 0 1 2}$ & $\mathbf{. 0 0 1 6}$ & $\mathbf{6 . 3 3}$ & $\cong \mathbf{2 . 7 6}$ \\
$\mathbf{1 8 ~ k m}$ & $\mathbf{2 3}$ & $\mathbf{. 0 0 7 3}$ & $\mathbf{. 0 0 1 2}$ & $\mathbf{. 0 0 1 7}$ & $\mathbf{5 . 2 9}$ & $\cong \mathbf{2 . 7 6}$ \\
$\mathbf{1 9} \mathbf{~ k m}$ & $\mathbf{. 2 7}$ & $\mathbf{. 0 0 8 1}$ & $\mathbf{. 0 0 0 9}$ & $\mathbf{. 0 0 2 2}$ & $\mathbf{6 . 2 8}$ & $\cong \mathbf{2 . 7 6}$ \\
$\mathbf{2 0} \mathbf{~ k m}$ & $\mathbf{. 1 8}$ & $\mathbf{. 0 0 5 4}$ & $\mathbf{. 0 0 0 8}$ & $\mathbf{. 0 0 1 8}$ & $\mathbf{3 . 5 0}$ & $\cong \mathbf{2 . 7 6}$ \\
$\mathbf{2 1} \mathbf{~ k m}$ & $\mathbf{. 1 5}$ & $\mathbf{. 0 0 5 1}$ & $\mathbf{. 0 0 1 0}$ & $\mathbf{. 0 0 1 9}$ & $\mathbf{3 . 3 3}$ & $\cong \mathbf{2 . 7 6}$ \\
$\mathbf{2 2} \mathbf{~ k m}$ & $\mathbf{. 1 2}$ & $\mathbf{. 0 0 4 8}$ & $\mathbf{. 0 0 1 2}$ & $\mathbf{. 0 0 1 9}$ & $\mathbf{3 . 1 1}$ & $\cong \mathbf{2 . 7 6}$ \\
$23 \mathrm{~km}$ & .06 & .0030 & .0011 & .0018 & 1.89 & $\cong 2.76$ \\
$24 \mathrm{~km}$ & .07 & .0033 & .0011 & .0019 & 2.10 & $\cong 2.76$ \\
$25 \mathrm{~km}$ & .08 & .0034 & .0011 & .0013 & 1.75 & $\cong 2.76$ \\
$26 \mathrm{~km}$ & .09 & .0044 & .0014 & .0015 & 1.82 & $\cong 2.76$ \\
\hline
\end{tabular}



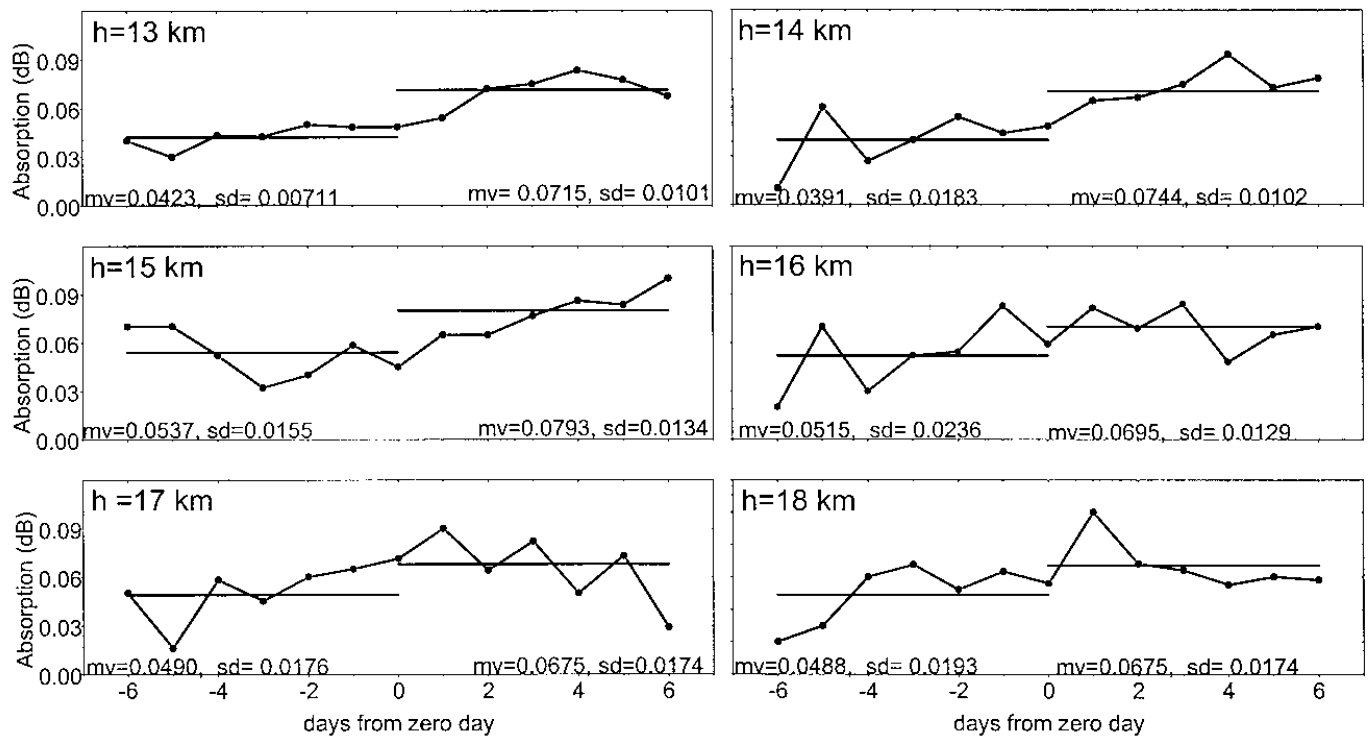

Fig. 1. Results from SEA for data set at noon in the range $13-18 \mathrm{~km}$ : statistically significant results were found at 13,14 and $15 \mathrm{~km}$ for which the difference between the mean values $(\mathrm{mv})$ of the ionospheric absorption are greater than both standard deviations $(s d)$ calculated before and after the «zero day».
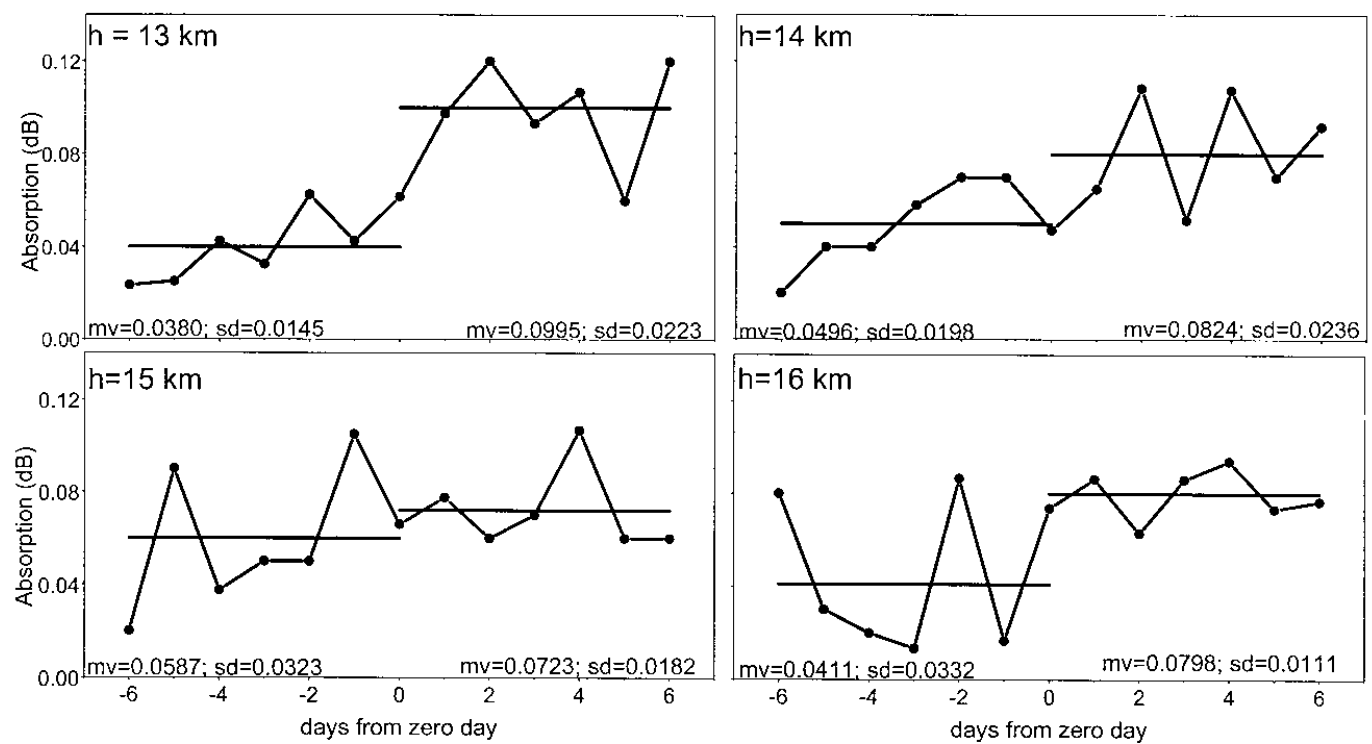

Fig. 2. Results from SEA for data set at midnight in the range $13-16 \mathrm{~km}$ : statistically significant results were found at 13,14 and $16 \mathrm{~km}$ for which the difference between the mean values $(\mathrm{mv})$ of the ionospheric absorption are greater than both standard deviations $(s d)$ calculated before and after the «zero day». 


\section{Results}

Tables I and II show the results of the multiregression analysis. For data set at $h=12.00 \mathrm{UT}$ (table I), the contribution of the temperature is greater than the contribution due to the solar and magnetic activity in the range $15-18 \mathrm{~km}$. For data set at $h=00.00$ UT (table II), the contribution of the temperature is greater than the contribution due to the solar and magnetic activity in the range $15-22 \mathrm{~km}$. Fisher's test, reported in the last two columns, shows that these results are statistically significant, the parameter $F$ being greater than $F_{\alpha}$ selected for a confidence level $=95 \%$.

Figures 1 to 4 show the results of SEA application for $h=00.00 \mathrm{UT}$ and 12.00 UT and for $l=13,14 \ldots 26 \mathrm{~km}$. Ionospheric absorption $(\mathrm{dB})$ and the days from $T_{\max }(h, l)$ or «zero day» are placed on the $y$ and $x$ axis, respectively. The horizontal lines represent the average levels of the ionospheric absorption (the numerical values are also reported on the plot with the corresponding standard deviations).

Different responses of the ionospheric absorption to the stratospheric temperature can be noted: at the lower stratospheric altitudes, from 13 $\mathrm{km}$ up to $16-18 \mathrm{~km}$, the ionospheric absorption on the average increases after the «zero day» (figs. 1 and 2), while at higher stratospheric altitudes, starting from $17-19 \mathrm{~km}$ up to $26 \mathrm{~km}$, the ionospheric absorption on the average decreases after the $T_{\max }$ $(h, l)$ day (figs. 3 and 4), independently of the time of the day ( $h=00.00 \mathrm{UT}$ and/or 12.00 UT). This different behaviour could depend on the different meteorological conditions in the stratosphere (e.g., the character of the meridional wind).

Many results are also statistically significant, the difference between the mean values of the ionospheric absorption being greater than both standard deviations calculated before and after the «zero day».
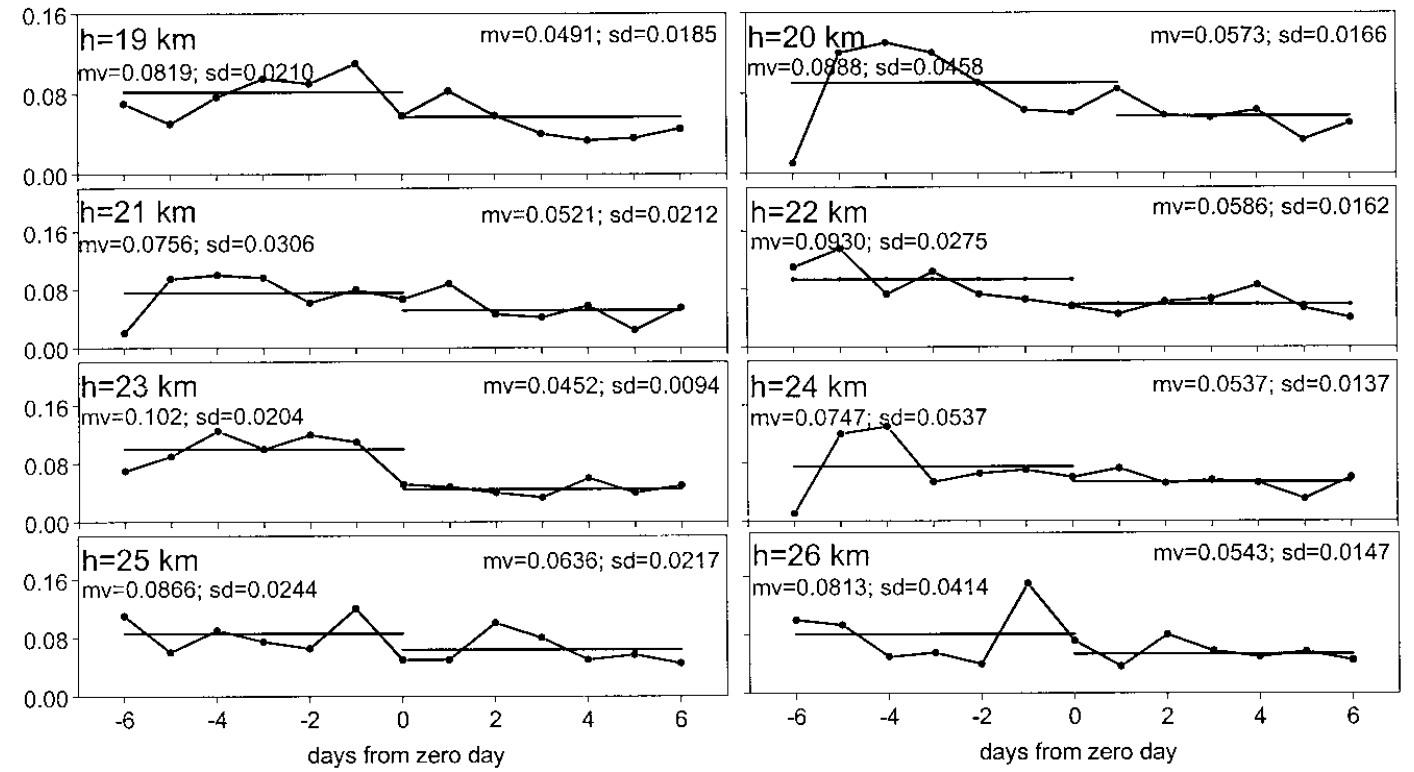

Fig. 3. Results from SEA for data set at noon in the range $19-26 \mathrm{~km}$ : statistically significant results have been found at 19, 22 and 23 for which the difference between the mean values $(m v)$ of the ionospheric absorption are greater than both standard deviations $(s d)$ calculated before and after the «zero day». 

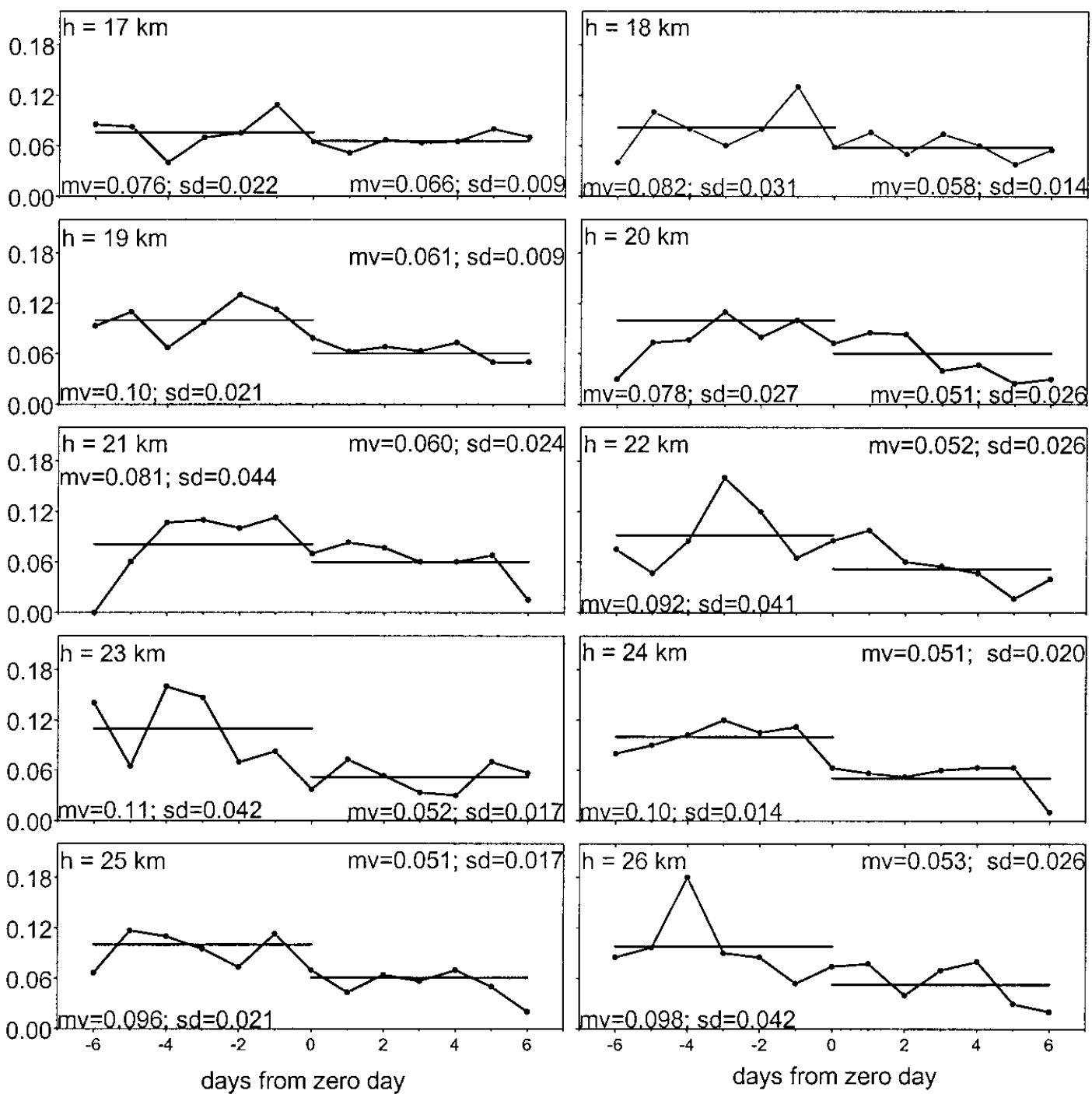

Fig. 4. Results from SEA for data set at midnight in the range $17-26 \mathrm{~km}$ : statistically significant results were found at 19,23,24, 25 and $26 \mathrm{~km}$ for which the difference between the mean values $(m v)$ of the ionospheric absorption are greater than both standard deviations $(s d)$ calculated before and after the «zero day».

\section{Conclusions}

Terra Nova Bay station is located close to or even inside the polar (southern) cusp region, where the geomagnetic field lines provide a direct connection between the ionosphere and the magnetosheath. It means that in this area the ionosphere should be predominantly controlled by the interaction with the magnetosphere. So it is difficult to distinguish between the ionospheric variability due to meteorological effects «coming from below», if they exist, from the 
effects caused by the influx of the energetic particles that increase the electron density and then the ionospheric absorption in the lower ionosphere (e.g., PCA phenomenon). Nevertheless, during the period under consideration (rather low solar activity, $F_{10.7}<100$ and quiet/ normal magnetic conditions, mean value of ap $(\tau)$ is about 10$)$ strong absorption events were not recorded: in fact, on the average, the absorption values ranged between $0.014 \mathrm{~dB}$ and $0.11 \mathrm{~dB}$. This could be why we pointed out the existence of a statistically significant signal of the stratosphere-ionosphere coupling (at least for some stratospheric levels) suggesting possible meteorological effects on the lower ionosphere.

In particular, the analyses performed on the short period of data simultaneously available gave the following main results:

- The ionospheric absorption at $30 \mathrm{MHz}$ shows a correlation with the stratospheric temperature variations occurring between 15$18 \mathrm{~km}$ (12.00 UT) and 15-22 km (00.00 UT). Moreover, Fisher's test confirms that these results are also statistically significant for a confidence level equal to $95 \%$ (tables I and II).

- The temporal trend of the ionospheric absorption related to the maximum stratospheric temperature depends on the height where this maximum occurs, by pointing out a sort of increasing or decreasing absorption behaviour if $T_{\max }(h, l)$ is in the lower or in the upper stratosphere, respectively. From the SEA applied to the cases under investigation, the separation level is found to be located around $17-19 \mathrm{~km}$. In fact, on the average, in the range $13-18 \mathrm{~km}$ (at $00.00 \mathrm{UT}$ and 12.00 UT) the ionospheric absorption increases after the «zero day» (figs. 1 and 2), and, on the contrary, in the ranges $19-26 \mathrm{~km}$ (at 00.00 UT and $12.00 \mathrm{UT}$ ) the ionospheric absorption decreases after the «zero day» (figs. 3 and 4). Moreover, for several levels between $13-26 \mathrm{~km}$. at $12.00 \mathrm{UT}$ and $00.00 \mathrm{UT}$ the result of stratosphere-ionosphere coupling is statistically significant.

Although this investigation does not deal with stratospheric warming events, some general considerations can be made. The existence of a daily absorption variability, i.e. maxima and minima recurring 2-4 days around the «zero day» (figs. 1, 2, 3 and 4) and, on the average, a growing absorption after the «referring epoch» (figs. 1 and 2), is similar to results obtained by Essex and Morton (1974) who applied the SEA to investigate the effect of stratospheric warming on the ionospheric absorption in the Southern Hemisphere.

The comparison between previous studies and the preliminary results here obtained suggests that further investigations need to confirm, if any, the coupling «coming from below», between the upper and middle atmosphere at polar latitudes, also by making use of total ozone content data, and meteorological parameters, such as the meridional and zonal wind (Lastovicka et al., 1990), and of longer time data series than those here analysed.

\section{Acknowledgements}

This study was supported by the Italian Program of Antarctic Researches (PNRA). The authors thank Dr. L. Perrone and Mr. M. Cerrone for the Riometer stations measurements and the derived ionospheric absorption data, and the Space Environment Center (NOAA, U.S. Dept. of Commerce, Boulder-CO, U.S.A.) for supplying the solar flux $F_{10.7}$ data.

\section{REFERENCES}

BACCI, G. and A. Pellegrini (1996): Operational meteorology at Terra Nova Bay, in Italian Geophysical Observatories in Antarctica, edited by A. MELONI and A Morelli (Istituto Nazionale di Geofisica, Roma), 151-162.

Bossolasco, M. and A. Elena (1963): Absorption de la couche $D$ et temperature de la mesosphère, C.R. Acad. Sci., Paris, 256, 4491-4493.

Bossolasco, M. and A. ElenA (1967): Stratospheric warmings and ionospheric absorption in winter, Geophys. Meteorol.,16, 45-48.

De Franceschi, G., A. DE SANTIS and L. Perrone (1997): Analysis of riometer data recorded at Terra Nova Bay, Antarctica, in Conference Proceedings of Solar Terrestrial Predictions Workshop, edited by G. Heckman, K. Marubashi, M.A. Shea, D.F. SMarT and R. THOMPSON, 431-434.

Essex, E.A. and F.W. MORTON (1974): Stratosphericionospheric coupling in the Southern Australian region, J. Atmos. Terr. Phys., 36,1945-1956. 
FRASER, G.J. and M.R. THORPE (1976): Experimental investigations of ionospheric/stratospheric coupling in southern mid latitudes -1 . Spectra and cross-spectra of stratospheric temperatures and the ionospheric $f_{\min }$ parameter, J. Atmos. Terr. Phys., 38, 1003-1011.

GRIGIONI, P. (1996): The Italian Antarctic meteorological observatory: technical activity and some climatological results, in: Italian Geophysical Observatories in Antarctica, edited by A. MELONI and A. MORELLI (Istituto Nazionale di Geofisica, Roma), 135-149.

KAZIMIROVSKY, E.S. and V.D. KoKOUROV (1991): The tropospheric and stratospheric effects in the ionosphere. A review, J. Geomagn. Geoelectr. (Japan), 43 (Suppl.), 551-562.

KershengOlts, S.Z. (1986): Stratosphere-ionosphere coupling, Ph.D. Thesis, Institute of Cosmophysics and Aeronomy, Siberian Department of U.S.S.R. Academy of Sciences, Jakutsk
LASTOVICKA, J., D. PANCHEVA and X.J. ZHANG (1990): On some difference in the behaviour of the upper and lower part of the lower ionosphere in relation to meteorological parameters, Ann. Geophysicae, 8 (9), 599-608.

Perrone, L. and G. De Franceschi (1999): A correlation study between time-weighted magnetic indices and the high latitude ionosphere, Phys. Chem. Earth (C), 24 (4), 389-392.

SHAPLEY, A.H. and W.J.G. BEYNON (1965): Winter anomaly in the ionospheric absorption and stratospheric warming, Nature, 206 (4990), 12421243.

TAubenheim, J. (1983): Meteorological control of the D-region, Space Sci. Rev., 34, 397-411.

WICKWAR, V.B. and H.C. CARLSSON (1999): Ionospheric and thermospheric couplings: vertical, latitudinal and longitudinal, J. Atmos. Sol. Terr. Phys., 61, 141-152. 